\title{
Design and Research on Computer Bilingual Teaching Network Support Platform Based on CDIO
}

\author{
Jun Rao \\ Tianjin University of Finance and Economics, China \\ rjnew@sina.com
}

Keywords: CDIO; Learning autonomy; Bilingual teaching; Network support platform

\begin{abstract}
This paper introduces the concept of learning autonomy proposed in the CDIO education concept. By analyzing the shortcomings in the practice of bilingual teaching, this paper points out the necessity of the construction of the bilingual teaching network platform. Then analyzes the existing problems in the construction of the network teaching platform, and puts forward the feasibility of constructing the bilingual teaching network platform under the guidance of CDIO educational idea. Taking the bilingual course of database as an example, the design and implementation process of CDIO concept network teaching platform are expounded in detail. Practice shows that the use of the teaching platform, can effectively improve the enthusiasm of students to learn, in the development of students active learning to promote the significance.
\end{abstract}

\section{Introduction}

CDIO education concept was founded by the Massachusetts Institute of Technology and other four universities, designed to cultivate the model through the reform and then cultivate students basic knowledge, personal ability, interpersonal team capacity and system education reform concept. CDIO means Conceive, Design, Implement, and Operate. It is the product development to the product operation, maintenance and waste of the whole life cycle as the carrier, the establishment of integrated support and organic link between the curriculum system, so that students in an active and practical way to learn [1]. CDIO concept systematically put forward 12 operational standards for the full implementation of education, inspection and evaluation provided a guarantee. Kang [2] introduced the 12 standards, including the standard 8 - active learning, highlighting the "student as the main" educational point of view. Active learning refers to the learners in a certain factor driven by the content of the study are interested in, from the heart is willing to learn and explore the process. For active learners, the motivation of their learning from their own interests, rather than outside persecution, will be devoted to learning, so that learning efficiency. Passive learning refers to the process of forced to learn from the pressure of the outside world. For passive learners, it is boring on the content of the study, encountered difficulties and too, not seeking solution, resulting in lower learning efficiency. Therefore, the key to teaching and learning is how to stimulate students to take the initiative to learn the ability.

\section{Current Situation}

In 2001, the Ministry of Education had put forward, "To improve the international competitiveness of China's higher education, information technology and other countries in the development of much-needed professional areas to carry out bilingual teaching." Called by the Ministry of Education, many colleges and universities in some professional courses in the practice of bilingual teaching. The so-called "bilingual teaching" refers to the teacher to complete the use of two languages to complete the teaching process. At present, the main domestic mainly refers to the teaching of English-based [3], the main form of three kinds: the use of English textbooks, Chinese blackboard, Chinese to explain; using English textbooks, English blackboard, Chinese to explain; use of English textbooks, English to explain (complete English). For students of computer science, proficient in English is not only in the international IT industry "survival" conditions, but also determine the level of personal development of the key factors. 
According to the survey, the current college bilingual teaching practice, the ability of students to read English is also very problematic: slow, cannot read or cannot complete the teacher's reading tasks on time [4]. This not only affects the teacher's schedule, but also reduces the enthusiasm of students to learn, resulting in poor teaching effectiveness. Although some scholars [5] to explore the bilingual teaching, but in the implementation of the students by the level of foreign language constraints, it is difficult to achieve the desired teaching effect. With the development of the Internet, the traditional teaching model is undergoing network change, and many courses have established a supporting network teaching platform, and as an extension of traditional classroom teaching. However, the current construction and use of network teaching platform there are some problems, such as platform construction is in formalism with poor content, and so on[6].

Therefore, the construction of CDIO-based network-assisted bilingual teaching platform, so that students access to the original computer expertise, for the cultivation of students' ability and future career development are of great significance: (1) the use of foreign excellent teaching materials, sharing abroad (2) to provide students with the opportunity to learn professional foreign language and improve their international communication skills; (3) to develop the habit of reading English literature, improve professional English reading ability, to overcome the fear of English.

\section{Design of Network Support Platform}

Main Content. Bilingual teaching has its own obstacles to go beyond, heavy materials, limited hours, a lot of reading, different from the Chinese textbook problem-solving ideas, close to the example of life exercises. How to complete the knowledge point of the professor at the same time, but also aims to improve the practical application of English ability, a large number of tasks need students to complete their own undergraduate learning habits to highlight their importance.

We adjust the face to face and the contents of the classroom configuration, taught to guide the main, rather than the main inculcation of teaching, to provide adequate teaching resources for students to self-study. Classroom lectures focus on the laws of physics and the concept of explanation, to help students to establish the knowledge system, ask questions to inspire students to think, induction, comprehend.

Objectives. The goal is based on the discipline, professional knowledge. For students to create a foreign language, with a good atmosphere of foreign languages. While the bilingual teaching related to the curriculum more rationalized, the relevant provisions of a more systematic and structured. So that the effect of bilingual teaching is mentioned, students can most accurately understand and touch the computer core and cutting-edge information, so as to achieve that students are foreign language skills, but also to enable students to have a strong academic capacity, in order to achieve higher Education "internationalization", cultivate new "compound talents", and accelerate the laying of a good foundation for higher education and international standards in China.

Some Key Issues to be Solved. These are current problems of network teaching platform:

Formatted content and lack of attraction. Some network teaching platform content in addition to containing the contents of the format, such as: syllabus, teachers, etc., and then add the courseware upload and download or online testing and some basic applications, More limited in the text of this single media, the lack of vivid teaching resources and the extension of the course content, the attraction of students is not strong, cannot stimulate students to use the platform of enthusiasm, the platform is useless.

Content is obsolete and can't be updated timely. Some of the network teaching platform after the completion of construction, long-term in a state of no update. Even the changes in teaching materials, courseware changes, and even the outline has been amended, these changes in the platform did not change, the platform obsolete, few students use.

The students' learning autonomy is not strong. A survey [7] shows that only $18.58 \%$ of college students spend more than three hours each week to study online. More than half of the students Used in the network to learn the time accounted for the proportion of all Internet access less than $1 / 4$. It can be seen that the proportion of students who really use the Internet to study is not very 
high. Therefore, how to increase the students take the initiative to learn the time to become the key to the construction of network teaching platform.

\section{Implementation}

In order to make up for the low level of students' foreign language ability in bilingual teaching and to prevent the recurrence of the current network teaching platform, we construct the bilingual teaching network supporting platform under the guidance of CDIO concept, with students as the main body and reconstructing the teaching system.

The platform is divided into teacher platform and student platform. Teacher platform to log in by the teacher, mainly to complete the maintenance of various teaching resources, job correction, teaching information release and online Q \& A and other work, and detailed records of teachers' online time, Q \& A time and other work, this platform is not done More discussion. Student platform, that is, the main interface of the teaching platform, not only contains the traditional platform provided by the functions, such as: a variety of teaching resources to browse and download, student job upload, online testing, etc., also provides students to stimulate learning function, such as : Student works upload and evaluation, certification and competition information, mutual supervision and other functions, and record students online learning time, online testing and other learning situation.

This paper focuses on the platform and other teaching platform differences, mainly to develop students' active learning aspects of the functional modules.

Teaching Resources. Similar to other teaching platforms, the platform's teaching resources module also provides a variety of teaching resources, such as lesson plans, courseware and other downloads, but the difference is that our teaching resources both the overall resources of the overall presentation, but also with the curriculum Chinese and English courseware, Chinese and English curriculum video and other resources to facilitate students in the classroom outside the study, an excellent solution to the students a low level of foreign language, class can not understand the problem, so that students can follow the course at any time to review the course content.

Homework Examination. This module will arrange the job placement and transfer to the network, so that students "have to" use the platform to understand the layout of the job and submit the job, so as to improve the frequency of students to use the platform; to provide students with plumbing function, On the bulletin board in real time to publish students to submit homework and complete the operation. In order to examine the students' knowledge of the degree of knowledge, set the unit test and module test and other online test function, can give students to participate in the test results list, when students have "unyielding" psychology, will stimulate their active learning, Do more enthusiasm for practice.

Certification and Competition. This module provides the students with the relevant information to participate in the certification exam and the competition so that this part of the students do not have to concentrate too much on the search of these information, can be energetic to invest in the ability to improve. For contested students, we will be on the platform in the form of a floating window to commend to encourage other students.

Students' Works Show. The module provides students with a space to show their learning outcomes and can vote for their favorite works and view the list of works. This greatly enriches the fun of the teaching platform, attracting students 'attention, from the level of interest to improve students' initiative to learn the driving force.

Interactive discussion. This module sets the teacher duty room and student duty room to achieve online $\mathrm{Q} \& \mathrm{~A}$. The teacher duty room is composed of members of the teaching team, according to the specified time for online Q \& A, student duty room is by students sitting, class students to take a group of three people as a group of respondents, from the "sense of responsibility" Forcing students to take the initiative to learn the same time the module also provides students with a free exchange of learning forums, and students can put forward their own comments on the curriculum comments and suggestions to enhance the interactive function of the network platform. 
Statistics. Students can not only understand their online learning time, learn the results, but also through the "mutual supervision" sub-module to understand other students' learning situation, to achieve the status of competitive learning. The construction of the teaching platform to students as the starting point, in addition to the use of traditional forms of text display, but also added animation, audio, video and other media forms, not only provides a wealth of network teaching resources, and the establishment of a real-time interactive platform, Notification, online submission and other forms of work to improve the frequency of students using the network platform to guide students to develop the habit of learning the network initiative..

\section{Summary}

We construct, track, evaluate, send, present and manage learning content and learning activities by constructing a bilingual teaching network platform under the CDIO vision. We have greatly improved and improved the effectiveness of project learning and students' learning ability in the network environment. At the same time, students can master the course knowledge, experience the process of project design and production, exercise the ability of collaborative learning and solve practical problems, and further improve the quality of bilingual teaching.

When the platform is put into use, the students' interest in learning is stimulated, the initiative of learning is obviously improved, and the teaching effect is improved obviously. The construction of the teaching platform and the successful application of other curriculum platform for the construction of a reference can become an effective complement to classroom teaching.

\section{References}

[1] Gu Pei, Bao Nengsheng, Kang Quanli etc. CDIO in China (Volume I)[J]. Research in Higher Education of Engineering, 2012.3:24-40.

[2] Kang Quanli, Lu Xiaohua, Xiong Guangjing. CDIO Outline and the Cultivation of Engineering Innovative Talents [J]. Journal of Higher Education Research, 2008.3:15-18.

[3] Zhang Li. Bilingual Teaching of the Compile Course[Z]. Beijing: School of Computer Science and Technology, Beijing University of Aeronautics and Astronautics, 2009.

[4] Yang Chuanming, Li Jiaxin. A Comparative Perspective: Bilingual Education in Singapore and Bilingual Teaching in Chinese Universities [J]. Heilongjiang Researches on Higher Education, 2008.7:58-60.

[5] Gao Dehui, Cao Jianqiu. Research on Bilingual Teaching of Computer [J]. Journal of Chongqing Jiaotong University (Social Sciences Edition), 2003.3(1):89-90.

[6] Yu Xi, Zhang Zhanshi. Construction and Application of Medical Bilingual Teaching Center Based on Network Platform [J]. China Medical Education Technology, 2009.23(3):295-297

[7] Liu Mingzhuo. Strategic Analysis and Model Construction of Network Course Availability Quality Assurance [J]. China Educational Technology, 2011.10:79-83 